\title{
Combined arterial switch and Senning operation for congenitally corrected transposition of the great arteries: Patient selection and intermediate results
}

Eric J. Devaney, MDa

John R. Charpie, $M D^{b}$

Richard G. Ohye, $\mathrm{MD}^{\mathrm{a}}$

Edward L. Bove, MD

From the Section of Cardiac Surgery, Division of Pediatric Cardiac Surgery, ${ }^{\mathrm{a}}$ and the Division of Pediatric Cardiology, Department of Pediatrics, ${ }^{\text {b }}$ University of Michigan School of Medicine, Ann Arbor, Mich.

Read at the Eighty-second Annual Meeting of The American Association for Thoracic Surgery, Washington, DC, May 5-8, 2002.

Received for publication June 6, 2002; revisions requested July 24, 2002; revisions received Aug 14, 2002; accepted for publication Aug 20, 2002.

Address for reprints: Edward L. Bove, MD, F7830 C.S. Mott Children's Hospital, 1500 East Medical Center Dr, Ann Arbor, MI 48109 (E-mail: elbove@umich.edu).

J Thorac Cardiovasc Surg 2003;125:500-7

Copyright $(\odot) 2003$ by The American Association for Thoracic Surgery

$0022-5223 / 2003 \$ 30.00+0$

doi: $10.1067 / \mathrm{mtc} .2003 .158$
Objective: Late results after traditional methods of repair of congenitally corrected transposition of the great arteries are poor. The combined arterial switch and Senning (double switch) operation may improve outcomes by using the morphologically left ventricle and mitral valve in the systemic circulation. In this report we review patient selection and intermediate results after the double switch operation for congenitally corrected transposition of the great arteries.

Methods: Since 1993, a total of 35 patients with congenitally corrected transposition of the great arteries with two ventricles of adequate size and no valvular pulmonary stenosis were potential candidates for a double switch operation. Eleven were not yet in need of further treatment, and 1 died during evaluation. The remaining 23 patients were entered into a protocol leading to anatomic repair. Their hospital records were reviewed, and follow-up data were obtained to evaluate early and intermediate outcomes.

Results: The 23 patients were candidates for anatomic repair because of right ventricular dysfunction or tricuspid regurgitation $(n=15)$ or associated uncorrected defects $(n=8)$. Pulmonary artery banding was performed in a total of 15 patients, either for left ventricular retraining $(n=11)$ or for congestive heart failure $(n=4)$. In 2 patients, aged 12 and 14 years, retraining was unsuccessful because of left ventricular dysfunction. Four patients with banding are currently awaiting repair. Eight patients proceeded to undergo double switch operations without preliminary pulmonary artery banding. To date, 17 patients have undergone double switch operations, with no early or late mortality. One patient required cardiac transplantation for progressive left ventricular failure after a preliminary banding and double switch operation done at 7 years of age. Ventricular function and tricuspid regurgitation remained stable or improved in all other cases. No patient has surgically acquired arrhythmias or significant residual hemodynamic conditions. All patients are alive and clinically well at a mean follow-up of 36 months (range 1 month- 8 years).

Conclusions: Congenitally corrected transposition of the great arteries with a normal pulmonary valve and two adequate ventricles can be managed with combined arterial switch and Senning operation with excellent intermediate results. Reconditioning the left ventricle may not be suitable for older patients. Late follow-up will be necessary to determine whether this management strategy provides a survival advantage for these patients.

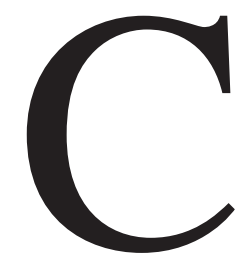

ongenitally corrected transposition of the great arteries (CCTGA) is a complex congenital heart defect characterized by the presence of both atrioventricular and ventriculoarterial discordance. Although this arrangement allows for a normal circulation in the absence of other defects, associated cardiovascular anomalies require treatment in most cases. The lesions most commonly associated with CCTGA include ventricular septal defect (VSD), pulmonary stenosis or atresia, 


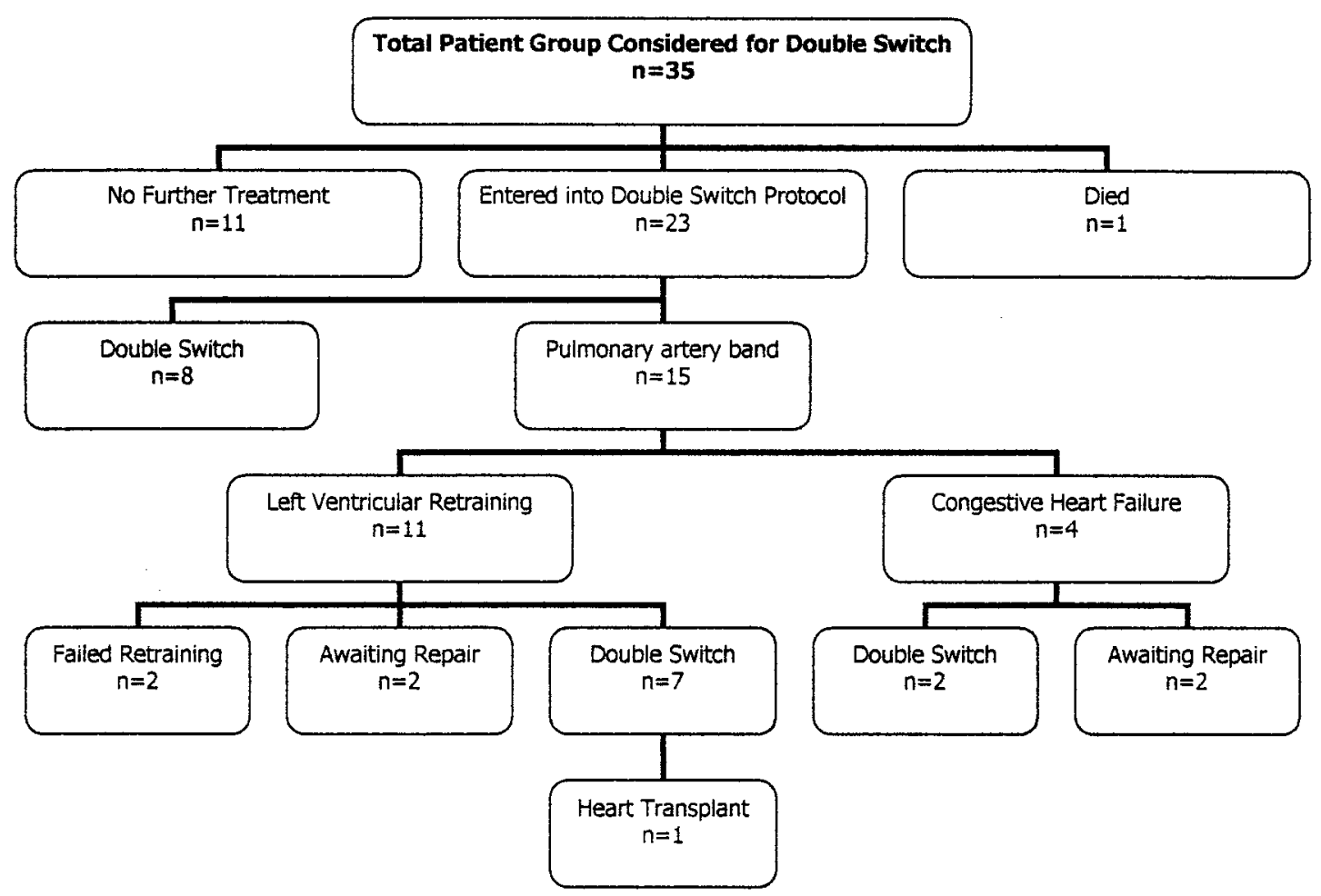

Figure 1. Fates of all 35 patients evaluated for anatomic repair.

tricuspid valve abnormalities, conduction disturbances, and single ventricle. ${ }^{1,2}$ Although the survival of patients with CCTGA is dictated largely by the associated defects, life expectancy is diminished for patients even with the isolated form of the condition. ${ }^{3-7}$ Dysfunction of the systemic (morphologically right) ventricle or systemic atrioventricular (tricuspid) valve tends to develop and worsen with time, which may lead to significant morbidity and mortality. ${ }^{8}$ The traditional surgical approaches to the treatment of patients with CCTGA have addressed the associated defects, either alone or in combination, while maintaining the morphologically right ventricle and tricuspid valve in the systemic circulation. The high late mortality associated with this approach has stimulated a number of groups to propose a more anatomic repair on the basis of the hypothesis that the establishment of atrioventricular and ventriculoarterial concordance would improve the long-term survival of patients with this anomaly. ${ }^{9-16}$ We have adopted this policy of anatomic repair for suitable candidates at our center. In this report we review patient selection and intermediate results after the combined arterial switch and Senning (double switch) operation for the subgroup of patients with CCTGA who have two ventricles suitable for biventricular repair and a normal pulmonary valve.

\section{Methods}

\section{Patient Selection}

Since 1993, when the first double switch operation was performed at C.S. Mott Children's Hospital, University of Michigan Health System, we have evaluated 35 patients with CCTGA with two ventricles of adequate size and no valvular pulmonary stenosis who were judged to be potential candidates for a double switch operation (Figure 1). For the purposes of this report, patients with pulmonary atresia or otherwise unsuitable pulmonary valves for an arterial switch were excluded from review to allow for analysis of a more homogeneous group. Although the indications for anatomic repair have evolved with increasing experience during the time frame of this study, we have generally recommended the double switch operation for patients with CCTGA who have associated defects requiring repair and for those patients with right ventricular dysfunction or systemic atrioventricular valve regurgitation. Earlier in our experience, those patients with nonrestrictive VSDs underwent pulmonary artery banding to protect the pulmonary vasculature and control symptoms of congestive heart failure before anatomic repair. Currently, pulmonary artery banding is performed only when other significant associated risk factors, such as prematurity, are present. For those patients with an unprepared left ventricle, the double switch procedure was performed after a preliminary pulmonary artery banding procedure to recondition the left ventricle.

At the time of referral, 11 patients were either clinically well without significant hemodynamic issues $(n=3)$, were under 
consideration for anatomic repair because of right ventricular dysfunction or tricuspid regurgitation but were not yet considered to require definitive treatment $(n=1)$, or were considered to be beyond an optimal age for left ventricular retraining $(n=7)$. One additional patient died at home during evaluation. Analysis of the remaining 23 patients provides the basis for this report. After approval by the institutional review board at the University of Michigan, the hospital records of all 23 patients were retrospectively reviewed, and follow-up data were obtained through clinic notes and contact with the patients, their families, or the treating cardiologists. Statistical analysis was performed with the SAS 8.1 software package (SAS Institute, Inc, Cary, NC). Preoperative and postoperative hemodynamic values were compared with the Wilcoxon signed-rank test.

\section{Surgical Technique}

Pulmonary artery banding. When preliminary pulmonary artery banding was performed to recondition the left ventricle, the main pulmonary trunk was exposed through an upper midline sternotomy approach. Under direct pressure monitoring and transesophageal echocardiographic guidance, the band was applied to achieve a left ventricular pressure of approximately half to two thirds of systemic levels. Because of the high degree of variability among these patients, optimal band tightness was not always achieved on the first effort and was often limited by the onset of left ventricular dysfunction. An effort was made to tighten the band sufficiently so that the interventricular septum moved to a midline position if possible. In a few cases a percutaneously adjustable band was placed by encircling the pulmonary artery trunk with a silicone elastomer tube that was left long enough to reach the subcutaneous tissue of the anterior chest wall. Subsequent band adjustments were then performed by exposing the band on the chest wall in the operating room. The left ventricle was considered adequately prepared for anatomic repair when its pressure was at least $80 \%$ of that in the right ventricle with normal ventricular function. Bands placed for palliation in patients with a nonrestrictive VSD were adjusted to lower the distal pulmonary pressure to half systemic level or less.

Anatomic repair: The double switch operation. The double switch operation was performed under standard bicaval cardiopulmonary bypass with moderate hypothermia $\left(25^{\circ} \mathrm{C}\right)$ and cold blood cardioplegia. The arterial switch was accomplished first with performance of the LeCompte maneuver and standard transfer of the coronary arteries. The pulmonary artery band was removed if present, and the pulmonary artery was divided at that site. A modified Senning procedure was performed in all cases, even when dextrocardia with situs solitus was present. The interatrial groove was widely dissected, and the mobilized atrial septum was augmented or replaced with a polytetrafluoroethylene patch.* The pulmonary venous pathway was routinely augmented with either autologous or heterograft (bovine) pericardium (Sulzer Carbomedics Inc, Austin, Tex). VSD closure was performed with sutures placed on the morphologically right ventricular side of the septum.

*Gore-Tex surgical membrane, registered trademark of W. L. Gore \& Associates, Inc, Flagstaff, Ariz.

\section{Results}

Twenty-three patients were entered into a protocol leading to anatomic repair because of right ventricular dysfunction or tricuspid regurgitation $(\mathrm{n}=15)$ or associated uncorrected defects $(n=8)$. To date, 17 patients have undergone a double switch operation (Table 1). Eight patients, ranging in age from 6 weeks to 5 years and all but 1 with nonrestrictive VSDs, progressed directly to the double switch procedure without pulmonary artery banding. Five of these patients had varying degrees of subpulmonic obstruction. This obstruction was clinically significant in 4 cases, and resection of muscular or fibrous tissue was possible in these patients. Six of the patients underwent the double switch procedure as a primary intervention. The youngest patient in this series (Table 1, case 9) underwent the double switch procedure at 6 weeks of age. She had significant right ventricular outflow tract obstruction and required placement of a conduit between the right ventricle and the pulmonary artery. She has required two subsequent conduit changes at the ages of 6 months and 1 year. The remaining 2 patients who did not require banding had undergone other operations before the double switch procedure. One patient (case 6) had undergone repair of a discrete aortic coarctation. The second patient (case 13) had undergone repair of interrupted aortic arch, VSD closure, and a modified DeVega tricuspid annuloplasty at another institution. This resulted in severe tricuspid stenosis with suprasystemic left ventricular pressure. At the time of the double switch procedure, the tricuspid annuloplasty suture was removed, with no additional valvuloplasty required.

Pulmonary artery banding was performed as initial palliation in 15 patients for the purpose of left ventricular retraining ( $\mathrm{n}=11$, age range 2 months- 14 years, median age 1 year) or to control congestive heart failure from excessive pulmonary blood flow $(\mathrm{n}=4$, age range 2 weeks- 2 months, median age 3 weeks). Among the 11 patients who underwent banding to recondition the left ventricle, the 2 oldest patients (aged 12 and 14 years) had failure of banding as a result of left ventricular dysfunction and required removal of the band. These patients were then considered to no longer be candidates for the double switch procedure. Four patients with banding are currently awaiting definitive repair, and 9 have proceeded to undergo the double switch procedure, with a median interval of 2 months (range 8 days- 5 months) between the two procedures.

Median age at time of the double switch procedure for all patients was 7 months (range 6 weeks-7 years). There has been no early or late mortality, although 1 patient (Table 1, case 8) who underwent preparatory pulmonary artery banding followed by anatomic repair at the age of 7 years required cardiac transplantation for progressive left ventricular failure. That patient underwent banding at an older age, 
TABLE 1. Patient profiles for 17 patients undergoing the double switch procedure

\begin{tabular}{|c|c|c|c|c|c|}
\hline Patient & Age (y) & Weight (kg) & Anatomy & Previous operations & Additional procedures \\
\hline 1 & 3.5 & 4.8 & $\begin{array}{l}\text { SLL, VSD, Ebstein anomaly, mild } \\
\text { subpulmonary stenosis }\end{array}$ & None & VSD closure \\
\hline 2 & 5.5 & 17.1 & $\begin{array}{l}\text { SLL, VSD, Ebstein anomaly, } \\
\text { subpulmonary stenosis }\end{array}$ & None & $\begin{array}{l}\text { VSD closure, subpulmonary } \\
\text { stenosis resection }\end{array}$ \\
\hline 3 & 4 & 13.6 & $\begin{array}{l}\text { SLL, restrictive VSD, Ebstein } \\
\text { anomaly }\end{array}$ & PA band & None \\
\hline 4 & 0.3 & 4.9 & SLL, VSD, CoA & $\begin{array}{l}\mathrm{PA} \text { band, } \mathrm{CoA} \\
\text { repair }\end{array}$ & VSD closure \\
\hline 5 & 0.3 & 6.1 & SLL, IVS, Ebstein anomaly, CoA & $\begin{array}{l}\text { PA band, } \mathrm{CoA} \\
\text { repair }\end{array}$ & None \\
\hline 6 & 3.5 & 12.2 & SLL, VSD, Ebstein anomaly, CoA & CoA repair & VSD closure \\
\hline 7 & 0.4 & 4.8 & $\begin{array}{l}\text { SLL, VSD, subpulmonary } \\
\text { stenosis, straddling MV }\end{array}$ & None & $\begin{array}{l}\text { VSD closure, subpulmonary } \\
\text { stenosis resection }\end{array}$ \\
\hline 8 & 7 & 16.4 & $\begin{array}{l}\text { SLL, VSD, Ebstein anomaly, } \\
\text { subpulmonary stenosis }\end{array}$ & $\begin{array}{l}\text { VSD closure, PA } \\
\text { band* }^{*}\end{array}$ & $\begin{array}{l}\text { Subpulmonary stenosis } \\
\text { resection }\end{array}$ \\
\hline 9 & 0.1 & 3.3 & $\begin{array}{l}\text { SLL, VSD, Ebstein anomaly, } \\
\text { severe subaortic stenosis }\end{array}$ & None & $\begin{array}{l}\text { Right ventricle-PA conduit, } \\
\text { VSD closure }\end{array}$ \\
\hline 10 & 0.3 & 6 & SLL, VSD & None & VSD closure \\
\hline 11 & 0.17 & 4.1 & SLL, IVS, Ebstein anomaly & PA band, ECMO* & None \\
\hline 12 & 0.8 & 8.8 & $\begin{array}{l}\text { SLL, VSD, subpulmonary } \\
\text { stenosis }\end{array}$ & None & $\begin{array}{l}\text { VSD closure, subpulmonary } \\
\text { stenosis resection }\end{array}$ \\
\hline 13 & 3 & 13 & $\begin{array}{l}\text { SLL, VSD, Ebstein anomaly, IAA, } \\
\text { subaortic stenosis }\end{array}$ & $\begin{array}{l}\text { IAA repair, VSD } \\
\text { closure, tricuspid } \\
\text { valvuloplasty }\end{array}$ & $\begin{array}{l}\text { Subaortic stenosis } \\
\text { resection }\end{array}$ \\
\hline 14 & 1.5 & 9.1 & SLL, IVS & PA band & None \\
\hline 15 & 0.4 & 5 & $\begin{array}{l}\text { SLL, restrictive VSD, Ebstein } \\
\text { anomaly, dextrocardia }\end{array}$ & PA band & VSD closure \\
\hline 16 & 0.5 & 3.9 & $\begin{array}{l}\text { SLL, restrictive VSD, Ebstein } \\
\text { anomaly }\end{array}$ & PA band & VSD closure \\
\hline 17 & 0.75 & 7.3 & SLL, VSD & PA band & VSD closure \\
\hline
\end{tabular}

$S L L$, Segmental anatomy characterized by situs solitus, levolooped ventricles, and levotransposition of the great arteries; $P A$, pulmonary artery; CoA, coarctation of aorta; IVS, intact ventricular septum; IAA, interrupted aortic arch.

*Procedures performed in two separate operations.

and although morphologically left ventricular pressure increased to systemic levels by 2 months after the band and a double switch procedure was successfully performed, transplantation was ultimately required for severe left ventricular diastolic dysfunction. Two patients (Table 1, cases 11 and 12) required a brief period of extracorporeal membrane oxygenation (ECMO) support after repair, one of whom (case 11) also required ECMO support before the double switch procedure. The other patient (case 12) had an uneventful early postoperative course but sustained a respiratory arrest after extubation and required a short period of ECMO support after resuscitation.

A comparison was made with Doppler echocardiography between preoperative hemodynamic values and those at discharge. Right and left ventricular function as well as tricuspid valve regurgitation ultimately remained stable or improved in all patients, with the exception of the patient who required transplantation (Table 2). Among the 9 patients with moderate to severe tricuspid valve regurgitation before anatomic repair, all had improvement to either no regurgitation or mild regurgitation. According to the standard 5-point echocardiographic scale of severity, tricuspid valve regurgitation was found to improve from a median preoperative score of $3+$ to a median postoperative score of $1+(P=.001)$. A trend suggesting postoperative improvement in right ventricular function was noted, although this did not reach statistical significance $(P=.06)$. All patients are alive and clinically well at a mean follow-up of 36 months (range 1 month-8 years). Although 4 patients had preexisting heart block, no patients have had surgically acquired arrhythmias or significant residual hemodynamic conditions after the double switch procedure.

\section{Discussion}

The optimal management of patients with CCTGA remains controversial. A number of studies have confirmed that life expectancy is substantially diminished even for patients who reach adulthood. ${ }^{17,18}$ The most common cause of death is congestive heart failure secondary to morphologically right (systemic) ventricular dysfunction, often associated 
TABLE 2. Right ventricular function and tricuspid valve regurgitation before and after anatomic repair

\begin{tabular}{|c|c|c|c|c|}
\hline \multirow[b]{2}{*}{ Patient } & \multicolumn{2}{|c|}{ Right ventricular function } & \multicolumn{2}{|c|}{ Tricuspid regurgitation } \\
\hline & Preoperative & Postoperative & Preoperative & Postoperative \\
\hline 1 & Good & Good & $3+$ & None \\
\hline 2 & Good & Good & $1-2+$ & $1+$ \\
\hline 3 & Mildly decreased & Good & $4+$ & $1-2+$ \\
\hline 4 & Good & Good & None & None \\
\hline 5 & Good & Good & None & None \\
\hline 6 & Good & Good & $4+$ & Trace \\
\hline 7 & Good & Good & $1+$ & $1+$ \\
\hline 8 & Mildly decreased & Mildly decreased & $3+$ & $1+$ \\
\hline 9 & Good & Good & $1+$ & $1+$ \\
\hline 10 & Good & Good & $1+$ & $1+$ \\
\hline 11 & $\begin{array}{l}\text { Moderately } \\
\text { decreased }\end{array}$ & Good & $4+$ & $2+$ \\
\hline 12 & Good & Good & $1+$ & None \\
\hline 13 & Good & Good & $3+$ & $1+$ \\
\hline 14 & $\begin{array}{l}\text { Severely } \\
\text { decreased }\end{array}$ & Mildly decreased & $3+$ & $1+$ \\
\hline 15 & Good & Good & $3+$ & $2+$ \\
\hline 16 & Mildly decreased & Good & $4+$ & $2+$ \\
\hline 17 & $\begin{array}{l}\text { Moderately } \\
\text { decreased }\end{array}$ & Good & $1+$ & $1+$ \\
\hline
\end{tabular}

with regurgitation of the tricuspid valve. Most patients are seen in early childhood with symptoms related to associated defects, however, and a decision must be made at that time whether to proceed with a traditional or an anatomic repair. Recent reports from several major centers have provided late follow-up data on patients with CCTGA undergoing traditional repair aimed at correcting the associated defects. ${ }^{19-21}$ Although early mortality was acceptable in these reports, continued attrition was significant, and overall survival at 10 years was surprisingly low at $60 \%$ to $70 \%$. Tricuspid valve regurgitation, generally related to a malformation similar to that seen in Ebstein anomaly, is common after traditional repair and may become worse as a result of a shift in the ventricular septum toward the left ventricle when left ventricular pressure is lowered. Although tricuspid regurgitation has been addressed by replacement of the systemic atrioventricular valve, this procedure is often unsuccessful in preventing or reversing right ventricular dysfunction. $^{22}$

Anatomic repair of CCTGA by the double switch operation has the appealing theoretic advantage of placing the morphologically left ventricle and mitral valve in the systemic circulation, thus relieving the hemodynamic burden on the right ventricle and tricuspid valve. In this study echocardiographic indices of right ventricular and tricuspid valve function remained stable or improved in all patients after anatomic repair, even among those with significant preoperative tricuspid valve regurgitation, thereby giving credence to this hypothesis. Additionally, many of the patients with significant tricuspid regurgitation demonstrated substantial improvement after pulmonary artery banding alone, supporting the notion that a shift in the position of the septum into the left ventricle causes or accentuates tricuspid valve regurgitation. As left ventricular pressure increases after banding, the septum shifts back toward the right ventricle, and tricuspid regurgitation improves. Several groups have reported excellent early results after the double switch procedure, bringing this procedure into the mainstream.9-16 Still, long-term data are lacking, and early enthusiasm must be tempered with careful and objective follow-up. Of note, one study failed to demonstrate any superiority of anatomic repair relative to traditional repair with respect to exercise testing. ${ }^{23}$

The large experience after atrial repairs for patients with dextrotransposition of the great arteries has emphasized the development of atrial arrhythmias and baffle obstruction as important late complications of these procedures. ${ }^{24,25} \mathrm{Al}-$ though neither of these problems has yet been seen in our series, it is well documented that the prevalence of atrial arrhythmias in particular increases with longer follow-up and that pacemaker therapy will ultimately be required for a significant percentage of these patients. It is not unreasonable to expect, however, that the management of atrial arrhythmias, particularly with modern pacing techniques, will be preferable to that of right ventricular failure and tricuspid regurgitation in patients with CCTGA.

Pulmonary stenosis occurs frequently in CCTGA. Although we excluded patients with pulmonary atresia or other types of significant pulmonary and subpulmonary stenosis from this analysis, several of our patients had mild 
degrees of subpulmonic obstruction. Anderson and colleagues ${ }^{26}$ observed that the nature of subpulmonic obstruction in these patients is commonly related to muscle bundles or fibrous tissue. In our experience, mild subpulmonic obstruction was not a contraindication to anatomic repair because it could generally be easily resected or, if especially mild, left alone.

Many of the patients in this series were older and were seen because of right ventricular failure, usually with tricuspid valve regurgitation and often without associated defects. As would be expected in such cases, the left ventricle was physiologically unprepared to sustain systemic pressure and resistance, and a period of reconditioning was required. Although pulmonary artery banding appears to be capable of providing adequate left ventricular training when done at an early age, it was not always suitable for older patients. In our series the 2 patients who had failure of this procedure underwent banding at an older age (12 and 14 years), and it is perhaps not surprising that banding was unsuccessful. Furthermore, another patient undergoing pulmonary artery banding at 7 years of age followed by anatomic repair subsequently required cardiac transplantation because of progressive left ventricular failure. Although the left ventricle in this patient was capable of eventually generating systemic pressure after banding, diastolic dysfunction limited the effectiveness of anatomic repair. It is well known that the mature myocardium is able to respond to an increase in afterload stress by hypertrophy, but true hyperplasia may no longer be possible. The inability to respond to pulmonary artery banding with hyperplasia and neovascular angiogenesis will ultimately limit the use of this procedure in older patients. The age after which the left ventricle can no longer appropriately respond to attempts at retraining cannot be determined in this small patient group, but there seems little doubt that the older patients fared worse.

\section{Clinical Inferences}

Selection of patients likely to benefit from anatomic repair has evolved with increasing experience. In our center, all patients requiring repair for associated defects now undergo a double switch repair when anatomically suitable. This includes those patients with isolated VSD. When the pulmonary valve is unsuitable for an arterial switch, anatomic repair by combined Senning and Rastelli procedures is preferred. Those patients who have significant right ventricular dysfunction or tricuspid regurgitation develop are evaluated for left ventricular retraining in preparation for the double switch procedure. Because the natural history of tricuspid regurgitation has been shown to be particularly poor, symptom-free younger patients with this condition are now strongly considered for banding and the double switch procedure even when right ventricular function remains well preserved. This may be particularly important to accomplish before older age precludes this approach. Older children and adults with an unprepared left ventricle are poor candidates for anatomic repair because of the inability to recondition the left ventricle, and cardiac transplantation should be considered if right ventricular dysfunction progresses in these patients.

In summary, anatomic repair with a combined Senning and arterial switch operation can be performed with acceptably low morbidity and mortality in patients with CCTGA with two adequate ventricles and a normal pulmonary valve. Early to intermediate follow-up has demonstrated preservation or improvement in right ventricular and tricuspid valve function. However, longer follow-up will be needed to determine whether this management strategy provides a survival advantage for these patients.

\section{References}

1. Allwork SP, Bentall HH, Becker AE, Cameron H, Gerlis LM, Wilkinson JL, et al. Congenitally corrected transposition of the great arteries: morphologic study of 32 cases. Am J Cardiol. 1976;38:910-23.

2. Van Praagh R, Papagiannis J, Grunenfelder J, Bartram U, Martanovic P. Pathologic anatomy of corrected transposition of the great arteries: medical and surgical implications. Am Heart J. 1998;135:772-85.

3. Friedberg DZ, Nadas AS. Clinical profile of patients with congenital corrected transposition of the great arteries: a study of 60 cases. N Engl J Med. 1970;282:1053-9.

4. Lundstrom U, Bull C, Wyse RK, Somerville J. The natural and "unnatural" history of congenitally corrected transposition. Am J Cardiol. 1990;65:1222-9.

5. Connelly MS, Liu PP, Williams WG, Webb GD, Robertson P, McLaughlin PR. Congenitally corrected transposition of the great arteries in the adult: functional status and complications. J Am Coll Cardiol. 1996;27:1238-43.

6. Voskuil M, Hazekamp MG, Kroft LJ, Lubbers WJ, Ottenkamp J, van der Wall EE, et al. Postsurgical course of patients with congenitally corrected transposition of the great arteries. Am J Cardiol. 1999;83: 558-62.

7. Graham TP Jr, Bernard YD, Mellen BG, Celermajer D, Baumgartner $\mathrm{H}$, Cetta F, et al. Long-term outcome in congenitally corrected transposition of the great arteries: a multi-institutional study. J Am Coll Cardiol. 2000;36:255-61.

8. Prieto LR, Hordof AJ, Secic M, Rosenbaum MS, Gersony WM. Progressive tricuspid valve disease in patients with congenitally corrected transposition of the great arteries. Circulation. 1998;98:9971005.

9. Yamagishi M, Imai Y, Hoshino S, Ishihara K, Koh Y, Nagatsu M, et al. Anatomic correction of atrioventricular discordance. $J$ Thorac Cardiovasc Surg. 1993;105:1067-76.

10. Imamura M, Drummond-Webb JJ, Murphy DJ Jr, Prieto LR, Latson LA, Flamm SD, et al. Results of the double switch operation in the current era. Ann Thorac Surg. 2000;70:100-5.

11. Karl TR, Weintraub RG, Brizard CP, Cochrane AD, Mee RB. Senning plus arterial switch operation for discordant (congenitally corrected) transposition. Ann Thorac Surg. 1997;64:495-502.

12. Yagihara $T$, Kishimoto $H$, Isobe F, Yamamoto F, Nishigaki K, Matsuki $\mathrm{O}$, et al. Double switch operation in cardiac anomalies with atrioventricular and ventriculoarterial discordance. J Thorac Cardiovasc Surg. 1994;107:351-8.

13. Ilbawi MN, Ocampo CB, Allen BS, Barth MJ, Roberson DA, Chiemmongkoltip $\mathrm{P}$, et al. Intermediate results of the anatomic repair for congenitally corrected transposition. Ann Thorac Surg. 2002;73:594-9.

14. Metras D, Kreitmann B, Fraisse A, Riberi A, Wernert F, Nassi C, et al. Anatomic repair of corrected transposition or atrio-ventricular discordance: report of 8 cases. Eur J Cardiothorac Surg. 1998;13: $117-23$. 
15. Sharma R, Bhan A, Juneja R, Kothari SS, Saxena A, Venugopal P. Double switch for congenitally corrected transposition of the great arteries. Eur J Cardiothorac Surg. 1999;15:276-81.

16. Reddy VM, McElhinney DB, Silverman NH, Hanley FL. The double switch procedure for anatomical repair of congenitally corrected transposition of the great arteries in infants and children. Eur Heart J. 1997; 18:1470-7.

17. Presbitero P, Somerville J, Rabajoli F, Stone S, Conte MR. Corrected transposition of the great arteries without associated defects in adult patients: clinical profile and follow up. Br Heart J. 1995;74:57-9.

18. Huhta JC, Danielson GK, Ritter DG, Ilstrup DM. Survival in atrioventricular discordance. Pediatr Cardiol. 1985;6:57-60.

19. Szufladowicz M, Horvath P, de Leval M, Elliott M, Wyse R, Stark J. Intracardiac repair of lesions associated with atrioventricular discordance. Eur J Cardiothorac Surg. 1996;10:443-8.

20. Biliciler-Denktas G, Feldt RH, Connolly HM, Weaver AL, Puga FJ, Danielson GK. Early and late results of operations for defects associated with corrected transposition and other anomalies with atrioventricular discordance in a pediatric population. J Thorac Cardiovasc Surg. 2001;122:234-41.

21. Termignon JL, Leca F, Vouhe PR, Vernant F, Bical OM, Lecompte Y, et al. "Classic" repair of congenitally corrected transposition and ventricular septal defect. Ann Thorac Surg. 1996;62:199-206.

22. van Son JA, Danielson GK, Huhta JC, Warnes CA, Edwards WD, Schaff $\mathrm{HV}$, et al. Late results of systemic atrioventricular valve replacement in corrected transposition. J Thorac Cardiovasc Surg. 1995; 109:642-52.

23. Ohuchi H, Hiraumi Y, Tasato H, Kuwahara A, Chado H, Toyohara K, et al. Comparison of the right and left ventricle as a systemic ventricle during exercise in patients with congenital heart disease. Am Heart J. 1999;137:1185-94.

24. Kirjavainen M, Happonen JM, Louhimo I. Late results of Senning operation. J Thorac Cardiovasc Surg. 1999;117:488-95.

25. Puley G, Siu S, Connelly M, Harrison D, Webb G, Williams WG, et al. Arrhythmia and survival in patients $>18$ years of age after the Mustard procedure for complete transposition of the great arteries. Am J Cardiol. 1999;83:1080-4.

26. Anderson RH, Becker AE, Gerlis LM. The pulmonary outflow tract in classically corrected transposition. J Thorac Cardiovasc Surg. 1975; 69:747-57.

\section{Discussion}

Dr Roger B. B. Mee (Cleveland, Ohio). The Ann Arbor group have presented, in a typically straightforward fashion, their 10year experience of 17 double switch procedures in a relatively young group of patients, with a mean age of 21 months at the time of surgery. This sample was culled from a cohort of 23 patients for whom intention to perform the double switch procedure was a commitment. Devaney and colleagues also included 12 other patients who were assessed but for various reasons have had no current surgical commitment. Among those 17 patients undergoing the double switch procedure there was no early mortality, but there were either 2 or 3 near misses-although I may have misinterpreted that from the article-with 2 patients requiring ECMO and 1 patient who has had a late heart transplant for left ventricular failure. After the double switch procedure, right ventricular dysfunction and tricuspid regurgitation regressed, as observed in other series.

I want to focus my questions on the areas of clinical concern; namely, those patients requiring retraining of the left ventricle, the pulmonary artery banding protocol and your philosophy on the interval between pulmonary artery band and the double switch procedure, the late left ventricular function in the 7 retrained and double-switched patients, and a discussion of the near misses and how they fit into this.
1. At pulmonary artery band for retraining, the stated intention in the article was to achieve a left ventricular pressure of half to two thirds of systemic pressure and to move the interventricular septum toward the midline position. Please expand on what parameters were used to determine that the pulmonary artery band was too tight. How often was very early left ventricular dysfunction, by which I mean that within 24 to 48 hours, identified, and how was that managed?

2. Do you in retrospect believe that the interval between pulmonary artery banding and the double switch procedure (mean 3 months, range 8 days-5 months) was just right, or was it possibly too short?

3. What is the actual late left ventricular function in the 6 of 7 patients with retraining pulmonary artery band who completed the double switch procedure and did not require subsequent heart transplantation? In your article the late left ventricular function is stated to be stable. Could you elaborate?

4. Of the 2 or 3 near misses-and please correct me on that - how many were patients who underwent left ventricular retraining, and what is their late left ventricular function?

Dr Devaney. To answer the first question, about how we know how tight the pulmonary artery band is, we really rely on the use of the intraoperative transesophageal echocardiography. In many cases we are able to identify a shift of the septum toward the midline when the band is optimally tightened. Really, we push it to tolerance. If we can tighten the band as much as $80 \%$, which is possible in some of the younger patients, then we do that.

How do we know if it is too tight? First, echocardiographically, left ventricular function worsens. We can see that clearly, that the left ventricle appears to be struggling. We can make this identification rather quickly in the operating room. In addition, systemic blood pressures tend to decrease, again a sign of left ventricular failure. I think that these assessments can generally be made in the operating room.

Although on the one hand I have said that we try to be aggressive, we also have used the silicone elastomer snare on many occasions where we thought that the left ventricle might be getting into trouble. In those cases we did back off and were a little more conservative, and use of this percutaneous snare really facilitated later readjustment.

Dr Mee. Can I interrupt you there just for a second? You described what you do in the operating room, but in our experience you may get out of the operating room looking very good, but by next morning or halfway throughout night the left ventricle is beginning to show dysfunction. I think it is equivalent to someone starting a sprint looking good at the starting line but not so good at the finishing line. Have you any comments on that? And if you get left ventricular dysfunction the next morning, what do you do?

Dr Devaney. In this series we have not had any problems that have been similar to that. Either we have identified problems in the operating room or, by and large, patients have done well. We really have not noticed problems with early left ventricular dysfunction.

The second question was regarding the banding interval. I think that we can rely on a lot of experience that we have in terms of conditioning the left ventricle for dextrotransposition of the great 
arteries. There are a lot of good data showing that in younger patients we can do rapid two-stage procedures, and the banding interval is on the order of 1 to 2 weeks. I think that for our younger patients that is generally what we have tried to do, and we have been able to do it successfully.

I certainly think that when you get into the older patients you cannot do that. You may be right that our banding interval may be too short. With respect to the 2 patients who had failure of left ventricular retraining, I should point out that they actually were given multiple chances and were followed up through several months' time with several readjustments performed. So we actually did try to give them a good opportunity. I think that you are right, however, that with the patients that are really borderline you would not want to err in the direction of too short of a banding interval.

You commented on the 2 patients who required ECMO. Those patients actually did not require ECMO primarily for cardiac support. It was not for left ventricular failure. Both patients actually had sustained respiratory arrests after the operation. Although it is hard to pinpoint, these events seem to have been related more to recent extubation and excessive sedation. After resuscitation, however, these patients did require a short period of ECMO support.

With respect to your last question, the late left ventricular function was good. We said that it was stable, meaning that really we have not had any patients who have had bad left ventricular failure.

Mr Marc R. de Leval (London, United Kingdom). I congratulate you on your superb results. I am surprised to hear that your decision making while banding the pulmonary artery for retraining is still based on the shift of the septum or simple measurement of left ventricular pressures.
For several years we have used pressure-volume loops during the procedure. The patients first go to the cardiac catheter laboratory before surgery to have a conductance catheter placed in the left ventricle for recording of the pressure-volume loops during the banding. I disagree with your suggestion to band as tightly as possible. If you do so, you damage the ventricle. It is actually sometimes necessary to band in two stages.

With regard to transplantation, I suggest that some patients with severe tricuspid valve regurgitation and poor right ventricular function can sometimes benefit from banding of the pulmonary artery. Two years ago we performed (in two stages) banding in a 55-year-old patient who was on the transplantation list. A year later she had mild tricuspid valve regurgitation and only mildly impaired right ventricular function.

Dr Devaney. I completely agree that the use of a conductance catheter and more sophisticated techniques certainly would benefit us when dealing with the patients that are borderline, meaning that they are slightly older and we are trying to figure out the correct banding tightness. We have no clinical experience at our center with the conductance catheter, but it sounds like a really outstanding idea.

With respect to your subsequent question, though, I was a little confused about exactly what you were asking. The 1 patient who underwent transplantation did undergo left ventricular retraining, and we considered the left ventricle to be fairly well conditioned. The ventricle was able to generate systemic pressures without apparent difficulty. The main problem was that severe diastolic dysfunction developed. I do not think that we understand diastolic dysfunction well enough at a molecular level to know really how to deal with it. 